\title{
Triplet-Sensitized Photodeprotection of Oligonucleotides in Solution and on Microarray Chips
}

by Dominik Wöll $\left.{ }^{\mathrm{a}}\right)$, Stefan Walbert ${ }^{\mathrm{a}}$ ), Klaus-Peter Stengele ${ }^{\mathrm{b}}$ ), Tom J. Albert ${ }^{\mathrm{c}}$ ), Todd Richmond $^{\mathrm{c}}$ ), Jason Norton $^{c}$ ), Michael Singer ${ }^{c}$ ), Roland D. Green*c), Wolfgang Pfleiderer ${ }^{a}$ ) and Ulrich E. Steiner*a)

a) University of Konstanz, D-78457 Konstanz, Germany

(e-mail: ulrich.steiner@uni-konstanz.de)

b) Chemogenix $\mathrm{GmbH}$, D-84568 Pleiskirchen, Germany

c) NimbleGen Systems Inc., Madison, WI, U.S.A.

(e-mail: rgreen@nimblegen.com)

Conditions and kinetics of triplet sensitization as a method for increasing the light sensitivity of photolabile protecting groups used for the photolithographic synthesis of oligonucleotide microarrays were quantitatively studied with the photolabile 2-(2-nitrophenyl)propyl protecting group in homogeneous solutions and on glass substrates by using laser flash photolysis, continuous illumination with HPLC analysis, fluorescence dye labelling, and hybridization. In terms of efficiency and avoidance of chemical side reactions, $9 H$-thioxanthen-9one was the most-suitable sensitizer. Both in solution and on a glass substrate, the photostationary kinetics were quantitatively modelled and the relevant kinetic parameters determined. While the sensitization kinetics was diffusion-controlled both in solution and on the chip, the photostationary kinetics was essentially of zero order only on the chip because here the triplet-quenching effect of the released photoproduct 2-(2-nitrophenyl)propene was suppressed as a consequence of the inhomogeneous reaction that took place in a narrow diffusion zone above the surface from where the photoproducts could quickly escape. The kinetic simulation allowed quantitative estimate of the density of reactive groups on the surface. It was further demonstrated that, with $9 \mathrm{H}$ thioxanthen-9-one as a sensitizer, high-density oligonucleotide microarrays of high quality can be produced with one-third of the normal exposure time.

Introduction. - Oligonucleotide microarrays are commonly synthesized by one of five methods: light-directed in situ oligonucleotide synthesis [1][2], ink-jet in situ oligonucleotide synthesis [3], photogenerated acid in situ oligonucleotide synthesis [4], electrochemical in situ oligonucleotide synthesis [5], or physical deposition of presynthesized oligonucleotides [6]. To date, the highest-density microarrays have been fabricated by using light-directed in situ oligonucleotide synthesis. Arrays manufactured with this process have been used for a broad range of studies and have become the most commonly used commercial microarrays.

To assure low error rates and short cycle times in the light-directed in-situ oligonucleotide process, microarray fabrication by light requires that photolabile protecting groups are cleaved in high yield in a reasonable time [7]. To meet these criteria, the light sensitivity of the photolabile protecting groups must be maximized. According to photochemical principles, this is tantamount to maximize the product $\varepsilon$. $\phi$, where $\varepsilon$ is the molar absorption coefficient at the wavelength of irradiation and $\phi$ is the photochemical quantum yield, i.e., the probability that a reaction occurs after a quantum of light has been absorbed.

Table 1 shows photolabile protecting groups that have been suggested or are already in use for DNA-chip synthesis [7-9]. For none of them does the product $\varepsilon \cdot \phi$

Konstanzer Online-Publikations-System (KOPS) 
Table 1. Customary Photolabile Protecting Groups for DNA Chip Synthesis and Their $\varepsilon \cdot \phi$ Values

\begin{tabular}{|c|c|c|c|}
\hline Acronym $^{a}$ ) & Structure & $\varepsilon \cdot \phi\left[\mathrm{M}^{-1} \mathrm{~cm}^{-1}\right]$ & $\overline{\text { Ref. }}$ \\
\hline npmoc & & 300 & b) \\
\hline nbeoc & & 300 & $\left.[7]^{c}\right)$ \\
\hline nppoc & & 95 & {$[8]$} \\
\hline dopeoc & & $<200$ & $\left.[9]^{\mathrm{c}}\right)$ \\
\hline
\end{tabular}

a) npmoc $=[(2$-nitrophenyl $)$ methoxy $]$ carbonyl $(=$ ONBOC $=[(2$-nitrobenzyl $)$ oxy $]$ carbonyl $)$, nbeoc $=[1-(6-$ nitro-1,3-benzodioxol-5-yl)ethoxy]carbonyl $(=\mathrm{MeNPOC}=(\alpha$-methyl-2-nitropiperonyloxy $)$ carbonyl $), \mathrm{nppoc}=$ [2-(2-nitrophenyl)propoxy]carbonyl, $\quad$ dopeoc $=[1-(3,5$-dimethoxyphenyl)-2-oxo-2-phenyl)ethoxy $]$ carbonyl $(=\mathrm{DMBOC}=(3,5$-dimethoxybenzoinoxy $)$ carbonyl $\left.) .{ }^{\mathrm{b}}\right) \mathrm{W}$. Pfleiderer, unpublished. $\left.{ }^{\mathrm{c}}\right)$ The $\varepsilon \cdot \phi$ values were extracted from the cited work by using the relation $t_{1 / 2} \approx \frac{\lg 2}{I N_{A} \varepsilon \phi}$ where $t_{1 / 2}$ is the half time of the reaction, $I$ is the photon flux and $N_{\mathrm{A}}$ is Avogadro's constant.

exceed a value of $300 \mathrm{M}^{-1} \mathrm{~cm}^{-1}$. In comparing the npmoc and the nbeoc groups, note that they show similar light sensitivity, although the absorption coefficient of nbeoc $\left(\varepsilon_{366} \approx 3000 \mathrm{M}^{-1} \mathrm{~cm}^{-1}\right)$ is more than 10 times the value of npmoc $\left(\varepsilon_{366} \approx 100 \mathrm{M}^{-1} \mathrm{~cm}^{-1}\right)$. Obviously the change in the molar absorption coefficient is compensated by a change in the photochemical quantum yield. This change demonstrates some principle limitation when attempting to optimize the light sensitivity of photoreactive chromophores by chemical substitution. We studied the photochemical mechanism of photolabile protecting groups of the 2-nitrophenyl type. By sensitizing the triplets of these photoreactive chromophores by triplet-triplet energy transfer with benzoate triplets as energy donors, we demonstrated that the triplet-excited 2-nitrophenyl chromophore is highly reactive. This observation opened up the possibility to optimize the factors of the product $\varepsilon \cdot \phi$ individually by using two separate compounds: a sensitizer with high $\varepsilon$, i.e., high light absorption, and a photoreactive group with high $\phi$, 
i.e., high reactivity. Both triplet-triplet energy transfer and singlet-singlet energy transfer (FRET) could in principle be employed. An advantage of triplet sensitizers, however, is the longer triplet lifetime, which allows energy donor and acceptor to attain a suitably close configuration during the excited-state lifetime of the energy donor.

This paper reports the results of a photokinetic study of photosensitized deprotection of [2-(2-nitrophenyl)propoxy]carbonyl-caged nucleotides in solution and under the conditions of photolithographic microarray synthesis on glass substrates.

Results. - Sensitization in Homogeneous Solution. To find suitable sensitizers, initial experiments were carried out in homogeneous solution. The triplet sensitizers were selected according to the following criteria. They should have $i$ ) their lowest triplet energy $E\left(\mathrm{~T}_{1}\right)$ above $E\left(\mathrm{~T}_{1}\right)$ of the photolabile chromophore, $\left.i i\right)$ a high yield $\phi_{\mathrm{ST}}$ of intramolecular intersystem crossing, iii) a small $\mathrm{S}_{1}-\mathrm{T}_{1}$ energy gap, so that they can be optically excited at the longest possible wavelength and simultaneous excitation of the nucleic acid bases is safely avoided, $i v$ ) a high extinction coefficient for the $\mathrm{S}_{0}-\mathrm{S}_{1}$ transition, and $v$ ) a long triplet lifetime.

According to these criteria and available photophysical-data collections [10], acridin-9(10H)-one and $9 H$-thioxanthen-9-one appeared to be the best choices. We tested them and the 2-ethyl derivative of $9 H$-thioxanthen-9-one in various solvents, such as $\mathrm{MeOH}, \mathrm{MeCN}, \mathrm{THF}$, and dioxane.

Laser Flash Photolysis. It is well known that the triplet states of acridin-9(10H)-one and $9 H$-thioxanthen-9-one are detectable by laser flash photolysis [8][11-15]. Because the triplet-energy transfer would lead to a reduction of the triplet lifetimes of the sensitizers, the study of triplet quenching by nppoc-protected compounds was an obvious experiment. We found nppoc-protected compounds to be effective quenchers of the tested sensitizers. Pertinent data $\left(k_{0}\right.$, the decay constant of the triplet in $\mathrm{O}_{2}$-free solution, and $k_{\mathrm{q}}$, the quenching constant) are reported in Table 2. Details of the laser flash photolysis experiments are given in [8]. During the nppoc-induced decay of the sensitizer triplets, the rise of a transient absorption around $400 \mathrm{~nm}$ was observed. Such a transient is typical for the aci-nitro form originating from an intramolecular shift of the benzylic H-atom to the nitro group [11]. In the solvents THF and dioxane, triplet deactivation was accompanied by the formation of chemical intermediates and some permanent bleaching of the sensitizers.

Table 2. Triplet Decay Constants $\mathrm{k}_{0}$ and Quenching Rate Constants $\mathrm{k}_{\mathrm{q}}$ of Triplet Quenching by nppoc-and npp-Protected Compounds

\begin{tabular}{lllll}
\hline Sensitizer & Reactant $\left.^{\mathrm{a}}\right)$ & Solvent & $k_{0} \cdot 10^{-4}\left[\mathrm{~s}^{-1}\right]$ & $k_{\mathrm{q}} \cdot 10^{-9}\left[\mathrm{M}^{-1} \mathrm{~s}^{-1}\right]$ \\
\hline 9H-Thioxanthen-9-one & nppoc-T & $\mathrm{MeOH}$ & 3.9 & 1.0 \\
2-Ethyl-9H-thioxanthen-9-one & nppoc-T & $\mathrm{MeOH}$ & 4.6 & 0.8 \\
9H-Thioxanthen-9-one & nppoc-T & $\mathrm{MeCN}$ & 2.8 & 3.2 \\
2-Ethyl-9H-thioxanthen-9-one & nppoc-T & $\mathrm{MeCN}$ & 2.1 & 2.6 \\
$9 H$-Thioxanthen-9-one & npp-Ac & $\mathrm{MeOH}$ & 3.9 & 1.4 \\
$9 H$-Thioxanthen-9-one & npp-Ac & $\mathrm{MeCN}$ & 2.8 & 4.2 \\
Acridin-9 $(10 H)$-one & npp-Ac & $\mathrm{MeCN}$ & 7.0 & 3.3
\end{tabular}

$\left.{ }^{a}\right)$ nppoc-T = 5'-O-\{[2-(2-nitrophenyl)propoxy $]$ carbonyl $\}$ thymidine, npp-Ac $=2$-(2-nitrophenyl)propyl acetate. 
Continuous Photolysis. To identify the products of triplet-sensitized photochemistry and to determine quantitative photokinetic data, the sample solutions were investigated under continuous irradiation with light of the 366-nm mercury line. Analysis of the UV spectra in the course of illumination revealed that, in dioxane or THF, the sensitizers photodecomposed rapidly. Thus, further investigations were restricted to $\mathrm{MeOH}$ and $\mathrm{MeCN}$.

Irradiation experiments employing acridin-9(10H)-one as a sensitizer and 2-(2nitrophenyl)propyl acetate (npp-Ac) as the photolabile compound revealed that the decomposition of npp-AC in the presence of the sensitizer is only slightly faster than without the sensitizer. On the other hand, in the mixed solution, the sensitizer itself decomposes faster than in a solution containing the sensitizer as the only solute. In the HPLC of the solution photolyzed in the presence of the sensitizer, a new peak appears showing an UV absorption spectrum similar to acridin-9(10H)-one, and can, thus, be assigned to some acridinone derivative. These observations indicate that, in the case of acridin-9(10H)-one, the strong triplet quenching observed in the laser-flash-photolysis experiment is only partially due to triplet-triplet energy transfer but mostly due to a chemical quenching of the sensitizer triplet.

With $9 H$-thioxanthen-9-one and 2-ethyl-9H-thioxanthen-9-one as sensitizers, the photoreaction of the nppoc-protected compound was clearly accelerated relative to the direct irradiation. As is demonstrated in Fig. 1 with a series of HPLC plots during irradiation of a mixed solution of $9 \mathrm{H}$-thioxanthen-9-one and nppoc- $\mathrm{T}$ in $\mathrm{NH}_{3}$-saturated $\mathrm{MeCN}$, the peak due to nppoc-T decreases with a concomitant increase of the peak of free thymidine, while the peak intensity of $9 H$-thioxanthen-9-one remains constant. The reaction products of the sensitized reaction are identical to those of the direct reaction. As was previously shown [11], photodecomposition of nppoc compounds can follow two different reaction pathways, depending on whether the primarily formed aci-nitro compound reacts from its protonated or deprotonated form (cf. Scheme). Only the $\beta$-elimination reaction from the anion leads to the desired deprotection of the substrate. In a solvent with little basicity, such as $\mathrm{MeCN}$, the addition of a base is necessary to steer the reaction in the desired direction of deprotection.

A quantitative comparison of the kinetics of the unsensitized and the sensitized photoreaction under stationary illumination is shown in Fig. 2. Here, the relative concentration of unreacted nppoc- $\mathrm{T}$ is plotted as a function of irradiation time. The strongly accelerating effect of the sensitizer is obvious. Both kinetic traces have been fitted on the basis of the photokinetic Eqn. 1 and its numerical integration. Here $c_{\mathrm{R}}$ and $\varepsilon_{\mathrm{R}}$ represent the concentration and molar absorption coefficient at the irradiation wavelength of the photolabile protecting group, $c_{\text {sens }}$ and $\varepsilon_{\text {sens }}$ the corresponding quantities of the sensitizer, $I_{0}$ the illumination intensity in Einstein per units of time and area, $d$ the optical path length of the cell, $F$ the illuminated area on the cell window, $V$ the total volume of the solution in the cell, and $A$ the total absorbance at the wavelength of irradiation. The first term in the brackets represents the kinetic contribution due to direct light absorption by the photolabile chromophore, which causes reaction with a photochemical quantum yield $\phi_{\text {dir }}$. The second term in the brackets represents the kinetic contribution of the sensitized reaction. In this term, the fraction represents the probability that a triplet-excited sensitizer molecule will be quenched by a photolabile chromophore. This expression depends on the rate constants 


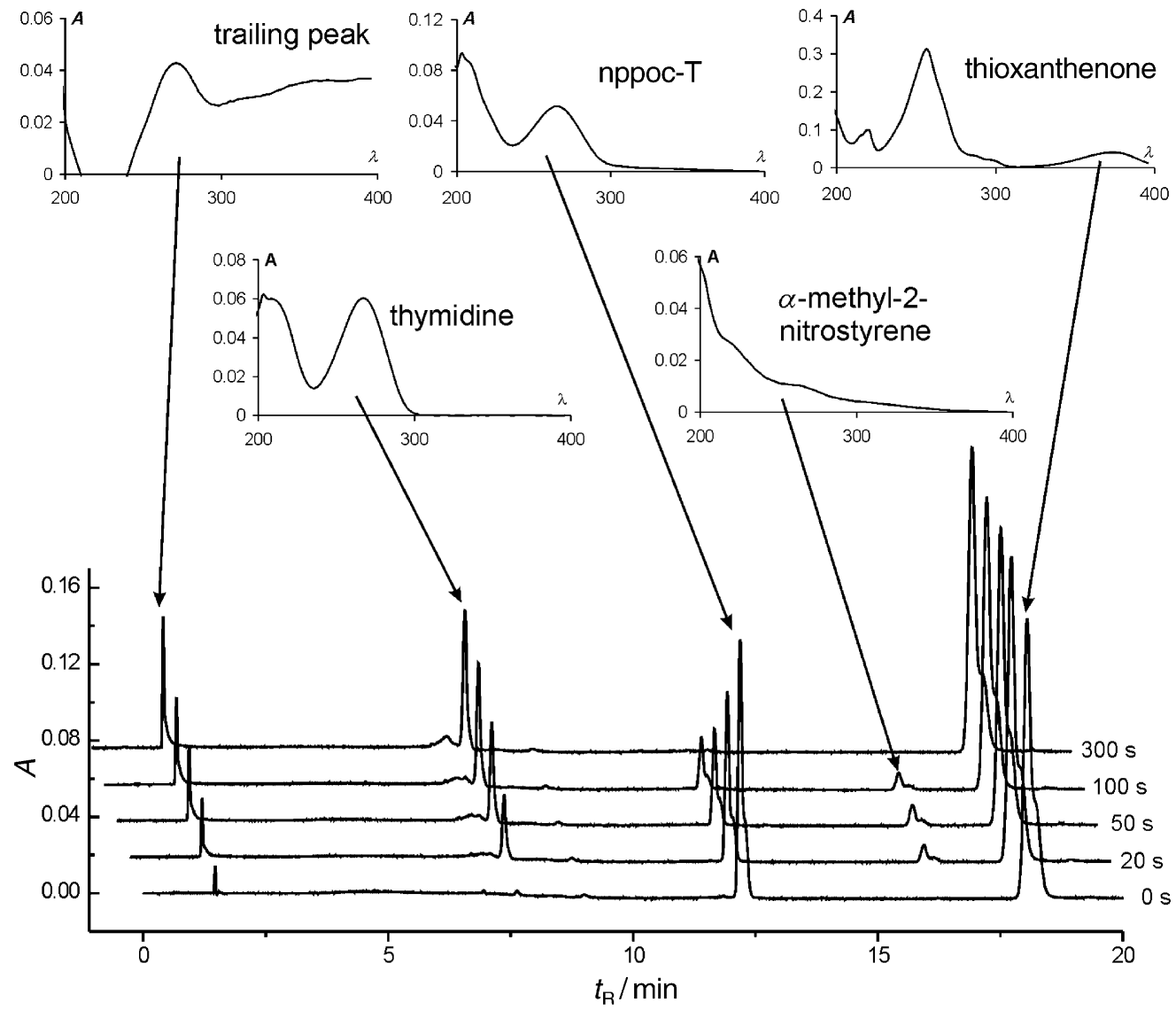

Fig. 1. HPLC Plots taken for solutions of nppoc- $T(0.091 \mathrm{~mm})$ and $9 \mathrm{H}-$ thioxanthen-9-one $(0.133 \mathrm{~mm})$ in $^{\mathrm{N} \mathrm{H}_{3^{-}}}$ saturated MeCN after given illumination times with radiation of $365 \mathrm{~nm}$. The upper part of the figure shows the UV spectra of the corresponding peaks. The peaks observed at retention times $t_{\mathrm{R}}$ of $7.63,12.19,16.1$, and $18.02 \mathrm{~min}$ correspond to free thymidine, nppoc-T, $\alpha$-methyl-2-nitrostyrene, and $9 H$-thioxanthen-9-one, resp. The trailing peak carries also some of the free thymidine, a phenomenon that is due to the difference in solvents of the sample $(\mathrm{MeCN})$ and the initial composition of the mobile phase $\left(\mathrm{H}_{2} \mathrm{O}\right)$.

$k_{0}$ and $k_{\mathrm{q}}$, both of which are known from the laser flash experiments. The term $k_{\mathrm{P}}\left(c_{\mathrm{R}, 0}-c_{\mathrm{R}}\right)$ in the denominator accounts for the fact that the photolabile chromophore in its cleaved-off form can also act as a triplet quencher with a quenching constant $k_{\mathrm{P}}$. The quantum-yield factor $\phi_{\text {sens }}^{0}$ comprises the combined probabilities of intersystem crossing in the sensitizer and of occurrence of the cleavage reaction after triplet-energy transfer to the photolabile chromophore has occurred.

$$
\frac{\mathrm{d} c_{\mathrm{R}}}{\mathrm{d} t}=-I_{0} \frac{d F}{V} \frac{1-10^{-A}}{A}\left(\varepsilon_{\mathrm{R}} c_{\mathrm{R}} \phi_{\mathrm{dir}}+\varepsilon_{\text {sens }} c_{\text {sens }} \phi_{\text {sens }}^{0} \frac{k_{\mathrm{q}} c_{\mathrm{R}}}{k_{0}+k_{\mathrm{q}} c_{\mathrm{R}}+k_{\mathrm{P}}\left(c_{\mathrm{R}, 0}-c_{\mathrm{R}}\right)}\right)
$$

Fitting the solution of Eqn. 1 to the observed kinetics allows the determination of $\phi_{\text {dir }}$ in the experiment without sensitizer and of $\phi_{\text {sens }}^{0}$ in the experiment with the 
Scheme

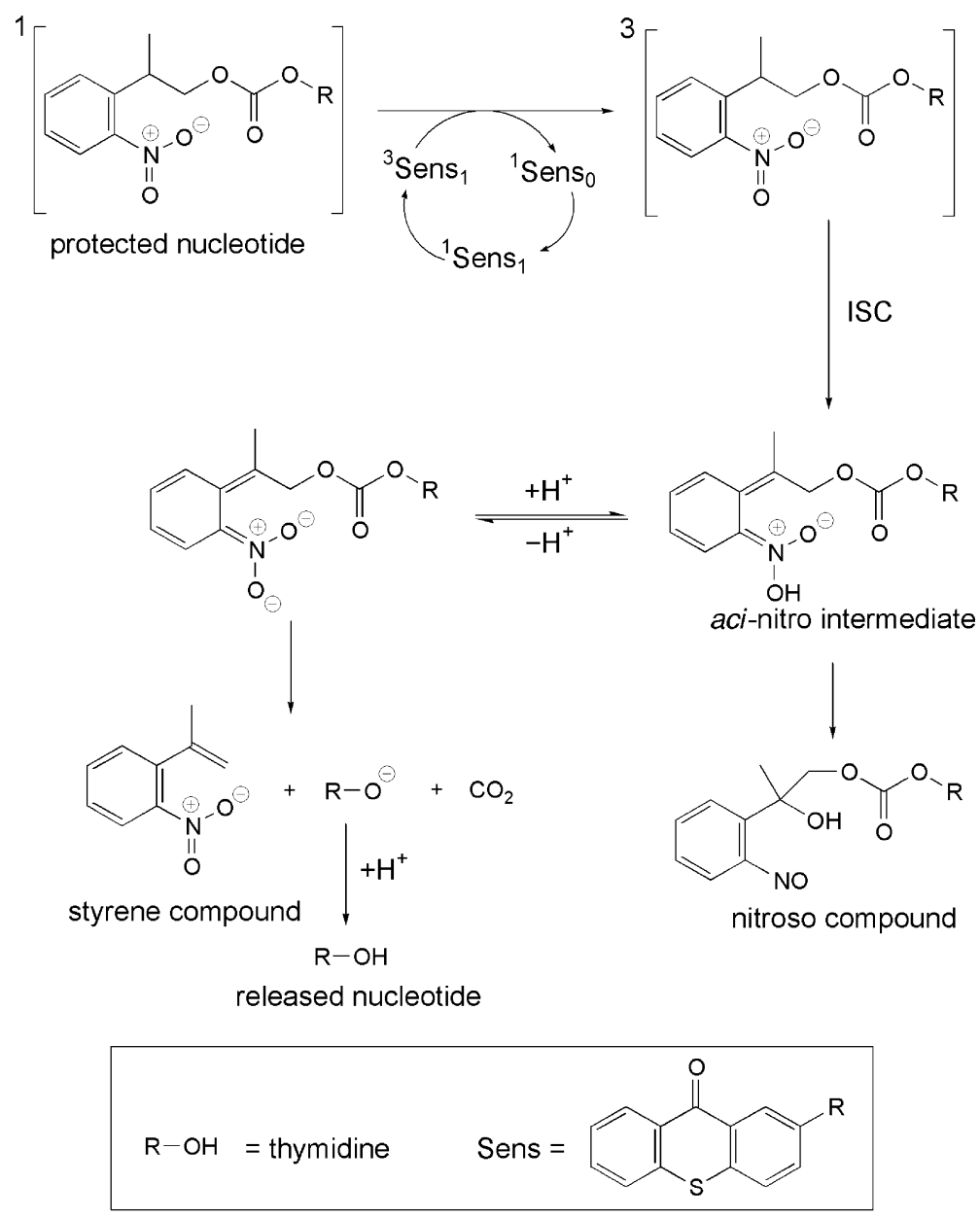

sensitizer. Fitting the kinetics of the sensitized reaction without taking quenching by the photoproduct of the photolabile chromophore into account yields behavior that is clearly incompatible with the observed one (cf. Fig. 2).

Table 3 lists the values of $\phi_{\text {dir }}, \phi_{\mathrm{sen} s}^{0}$, and $k_{\mathrm{P}}$ observed in the various experiments. The reproducibility of $\phi_{\text {sens }}^{0}$ in $\mathrm{N}_{2}$-saturated solutions was significantly less than of $\phi_{\text {dir }}$. We assign this observation to the sensitivity of the sensitizer triplet lifetime to traces of $\mathrm{O}_{2}$, which affects the rate of the sensitized reaction path but not of the direct one. Values of $\phi_{\text {sens }}^{0}$ can also be determined from photostationary kinetics experiments with aerated solutions if a term $\mathrm{k}_{\mathrm{q}, \mathrm{O}_{2}} \cdot\left[\mathrm{O}_{2}\right]_{\mathrm{air}}$ is added in the denominator of the term pertaining to sensitization in Eqn. 1. By using laser flash spectroscopy, $\mathrm{k}_{\mathrm{q}, \mathrm{O}_{2}} \cdot\left[\mathrm{O}_{2}\right]_{\text {air }}$ was measured to be $7.0 \cdot 10^{6} \mathrm{~s}^{-1}$ in $\mathrm{MeOH}$ and $1.1 \cdot 10^{7} \mathrm{~s}^{-1}$ in $\mathrm{MeCN}$. From the analysis of the photostationary kinetics in air-saturated solutions, the values obtained for $\phi_{\mathrm{sens}}^{0}$ are 


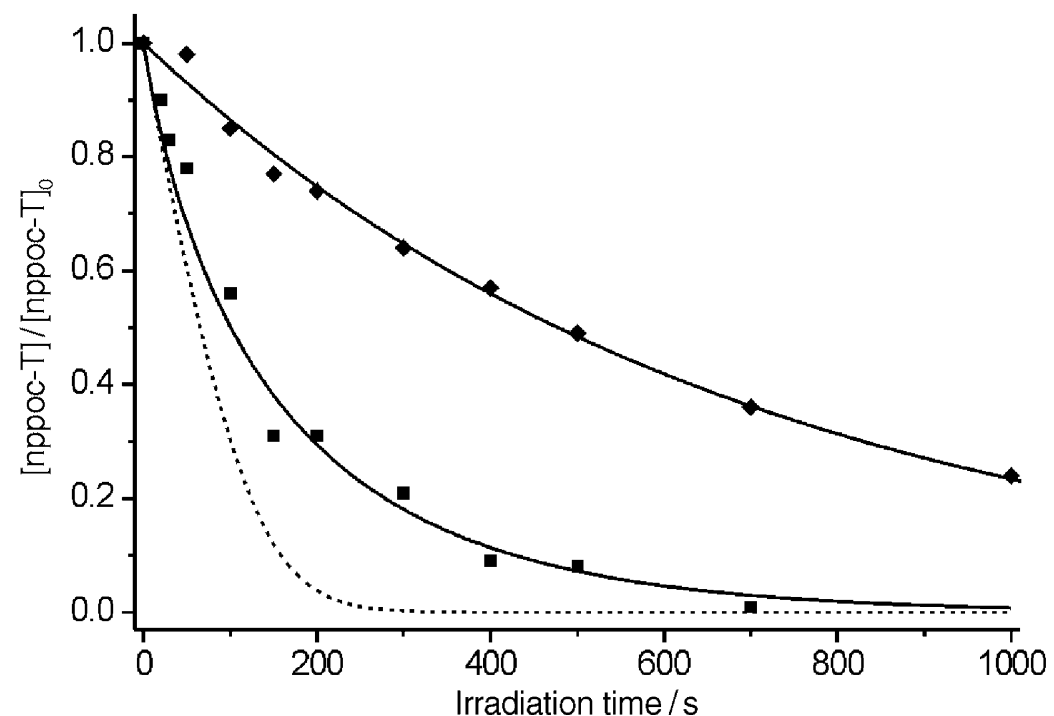

Fig. 2. Photokinetics of nppoc-T deprotection under stationary illumination at $366 \mathrm{~nm}$ in MeOH: direct photoreaction $\left([\right.$ nppoc- $\mathrm{T}]=0.087 \mathrm{mM}, I_{\mathrm{o}}=2.50 \cdot 10^{-8} \mathrm{E} \mathrm{cm}^{-2} \mathrm{~s}^{-1}$ ) and reaction photosensitized by $9 \mathrm{H}$ thioxanthen-9-one $\left([\mathrm{nppoc}-\mathrm{T}]=0.087 \mathrm{mM}\right.$, [thioxanthenone] $\left.=0.120 \mathrm{mM}, I_{\mathrm{o}}=2.50 \cdot 10^{-8} \mathrm{E} \mathrm{cm}^{-2} \mathrm{~s}^{-1}\right)$. The curves through the points are kinetic fits according to Eqn. 1. The dashed line is a kinetic simulation of the sensitized reaction, by using the same rate constants as in the fit of the experimental data but neglecting the effect of quenching by the photoproduct $\alpha$-methyl-2-nitrostyrene.

Table 3. Photokinetic Parameters Determined from the Stationary Illumination Experiments in Homogeneous Solution

\begin{tabular}{|c|c|c|c|c|c|c|c|c|}
\hline \multirow[t]{2}{*}{ Sensitizer } & \multirow[t]{2}{*}{ Reactant } & \multirow[t]{2}{*}{ Solvent } & \multirow[t]{2}{*}{$\phi_{\mathrm{dir}}$} & \multirow{2}{*}{$\begin{array}{l}\varepsilon_{\mathrm{dir}} \\
{\left[\mathrm{M}^{-1} \mathrm{~cm}^{-1}\right]}\end{array}$} & \multicolumn{2}{|l|}{$\phi_{\text {sens }}^{0}$} & \multirow{2}{*}{$\begin{array}{l}\varepsilon_{\text {sens }} \\
{\left[\mathrm{M}^{-1} \mathrm{~cm}^{-1}\right]}\end{array}$} & \multirow{2}{*}{$\begin{array}{l}k_{\mathrm{p}} \cdot 10^{-9} \\
{\left[\mathrm{M}^{-1} \mathrm{~s}^{-1}\right]}\end{array}$} \\
\hline & & & & & $\mathrm{N}_{2}$-sat. sol. & aerated sol. & & \\
\hline $9 H$-Thioxanthen-9-one & nppoc-T & $\mathrm{MeOH}$ & 0.30 & 247 & 0.3 & 0.31 & 4250 & 3 \\
\hline $\begin{array}{l}\text { 2-Ethyl-9H-thioxanthen- } \\
\text { 9-one }\end{array}$ & nppoc-T & $\mathrm{MeOH}$ & 0.30 & 247 & 0.1 & 0.19 & 4054 & 10 \\
\hline 9H-Thioxanthen-9-one & nppoc-T & $\mathrm{MeCN}$ & 0.33 & 225 & 0.5 & 0.59 & 4918 & 12 \\
\hline $\begin{array}{l}\text { 2-Ethyl-9H-thioxanthen- } \\
\text { 9-one }\end{array}$ & nppoc-T & $\mathrm{MeCN}$ & 0.33 & 225 & 0.3 & 0.43 & 4356 & 7 \\
\hline $9 H$-Thioxanthen-9-one & npp-Ac & $\mathrm{MeOH}$ & 0.17 & 217 & 0.1 & & 4250 & 4 \\
\hline 9H-Thioxanthen-9-one & npp-Ac & $\mathrm{MeCN}$ & 0.21 & 229 & 0.3 & & 4918 & 16 \\
\hline Acridin-9 $(10 H)$-one & npp-Ac & $\mathrm{MeCN}$ & 0.21 & 229 & 0.01 & & 5181 & 2 \\
\hline 9H-Thioxanthen-9-one & nppoc-T & $\mathrm{MeCN} / \mathrm{NH}_{3}$ & 0.45 & 267 & 0.5 & & $\left.4918^{\mathrm{a}}\right)$ & 6 \\
\hline $\begin{array}{l}\text { 2-Ethyl-9H-thioxanthen- } \\
\text { 9-one }\end{array}$ & nppoc-T & $\mathrm{MeCN} / \mathrm{NH}_{3}$ & 0.45 & 267 & 0.3 & & $\left.4356^{\mathrm{a}}\right)$ & 5 \\
\hline
\end{tabular}

a) Values assumed to be identical to those in $\mathrm{NH}_{3}$-free $\mathrm{MeCN}$.

generally somewhat larger than those from $\mathrm{N}_{2}$-saturated solution. In general, the values of $\phi_{\text {sens }}^{0}$ are similar to $\phi_{\text {dir }}$, indicating that the intersystem-crossing yield for these sensitizers is close to 1 and that the photolabile chromophore behaves similarly whether it receives its excitation energy by direct excitation or by triplet-triplet energy transfer. 
For acridin-9 $(10 H)$-one, however, $\phi_{\text {sens }}^{0}$ is very small, which indicates that quenching of the acridin-9(10H)-one triplet by the photolabile chromophore does not lead to effective reaction of the chromophore. Thus, as has been already noted above, the quenching mechanism is probably not only energy transfer but also a chemical reaction, whereby acridin-9(10H)-one is eventually converted to some derivative. The values of $k_{\mathrm{p}}$ are higher than the corresponding $k_{\mathrm{q}}$ values, which indicates that the nitrostyrene chromophore is a more-effective triplet quencher than the nitrobenzene chromophore. This deduction is quite reasonable, since the triplet energy of the more extended $\pi$ system of nitrostyrene is expected to be lower than that of nitrobenzene.

Deprotection Rates on Solid Substrate. To test whether the sensitizer could accelerate the deprotection rates of nppoc on a solid surface, we created arrays of features composed of nppoc-protected nucleotides attached to a glass substrate by a hydroxysilane layer. We exposed the arrays to increasing amounts of UV light by using a method described earlier [7]. After exposure, we coupled $C y-3{ }^{\circledR}$ amidite to the array to quantify the relative amounts of free $\mathrm{OH}$ groups produced by the irradiation. Fig. 3 presents the results. The sensitized system reached a maximum intensity after receiving $4 \mathrm{~J} / \mathrm{cm}^{2}$ while the unsensitized system reached a maximum after receiving $12 \mathrm{~J} / \mathrm{cm}^{2}$.

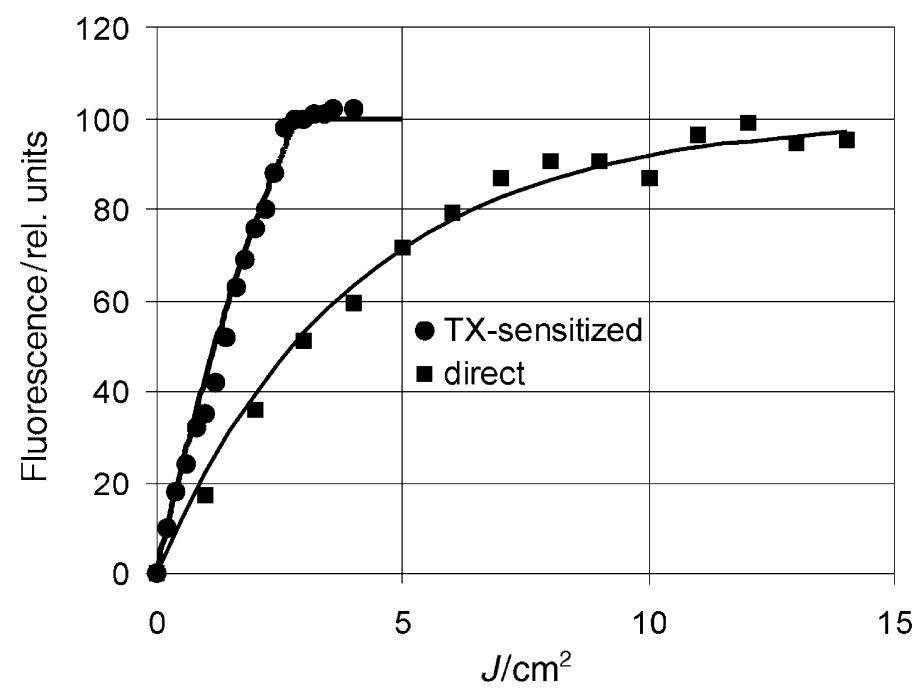

Fig. 3. Determination of deprotection rates on an array for direct and sensitized photoreaction $(\mathrm{TX}=9 H$ thioxanthen-9-one). In each case, arrays with a single layer of nppoc-T on a glass substrate were illuminated. Various features were exposed to light for different lengths of time. The extent of deprotection was measured by scanning the fluorescence intensity after coupling with $C y-3{ }^{\circledast}$ amidite. The solid lines result from theoretical simulations according to the photokinetic model described in the text.

The photokinetics on the solid surface is described by the rate law of Eqn. 2 for the surface density $\sigma_{\mathrm{R}}$ of photoreactive groups [16]. A simplification of the equation resulted from the reduction of the Lambert-Beer law to its linearized form, which is warranted because light absorption occurs only in a very narrow layer. This effect is 
obvious for the direct absorption of light by the photoreactive groups, because they are fixed on the solid surface. The kinetics of the direct process is represented by the first term in the parentheses. For the sensitizer, which is still in the homogeneous solution contacting the solid surface, it is also true, because only those molecules that are found in a narrow layer of a width that can be covered by translational diffusion of the sensitizer triplets during their excited-state lifetime become effective. This length is represented by the expression $\sqrt{\mathrm{D} \tau_{0}}$, where $D$ is the diffusion coefficient of the sensitizer and $\tau_{0}$ is the lifetime of the triplet under the conditions in solution. Finally, the fraction in the second term in the parentheses represents the probability that an excited sensitizer molecule, once it has reached the surface with the photolabile groups, will successfully transfer its energy to such a group. This probability approaches a limiting value of 1 for high enough values of $\sigma_{\mathrm{R}}$. Eqn. 2 can be derived in a rigorous way [16], and, thereby, the rate constant $k_{\mathrm{q}}^{\prime}$ for bimolecular energy transfer in a surface layer can be related to $k_{\mathrm{q}}$, the rate constant of bimolecular energy transfer in the volume. From this derivation, we know that the fraction expression is close to its limiting value until rather low values of $\sigma_{\mathrm{R}}$, i.e., high turnover rates of the photoreactive layer, have been achieved. In effect, this means that the energy transfer from solution to the chip surface is diffusion-controlled almost until the end of the reaction.

$$
\frac{\mathrm{d} \sigma_{\mathrm{R}}}{\mathrm{d} t}=-I_{0} \ln (10)\left(\varepsilon_{\mathrm{R}} \sigma_{\mathrm{R}} \phi_{\text {dir }}+\varepsilon_{\text {sens }} c_{\text {sens }} \sqrt{D \tau_{0}} \phi_{\text {sens }}^{0} \frac{k_{\mathrm{q}}^{\prime} \sigma_{\mathrm{R}}}{k_{0}+k_{\mathrm{q}}^{\prime} \sigma_{\mathrm{R}}}\right)
$$

In the experiment represented in Fig. 3, only relative surface densities of the photoreactive group were measured. Thus, it is appropriate to introduce the relative surface coverage $x$ of unreacted photolabile groups as defined in Eqn. 3 where $\sigma_{0}$ is the initial density at which photolabile groups are attached to the surface of the chip. By using this quantity, Eqn. 2 is converted to Eqn. 4 after the abbreviations $a_{\text {dir }}, a_{\text {sens }}$, and $b$ (Eqns. 5-7) have been introduced.

$$
\begin{gathered}
x \equiv \frac{\sigma}{\sigma_{0}} \\
\frac{\mathrm{d} x}{\mathrm{~d} t}=-a_{\mathrm{dir}} x-a_{\mathrm{sens}} \frac{b x}{1+b x} \\
a_{\mathrm{dir}} \equiv I_{0} \ln (10) \varepsilon_{\mathrm{R}} \phi_{\mathrm{dir}} \\
a_{\mathrm{sens}} \equiv \frac{I_{0} \ln (10) \varepsilon_{\mathrm{sens}} c_{\mathrm{sens}} \sqrt{D \tau_{0}} \phi_{\mathrm{sens}}^{0}}{\sigma_{0}} \\
b \equiv \frac{k_{\mathrm{q}}^{\prime} \sigma_{0}}{k_{0}}
\end{gathered}
$$

In Fig. 3, the dose $\Theta$ of light per unit area was used as a variable instead of the time $t$. These variables are interrelated by Eqn. 8 , where $f_{\mathrm{EJ}}$ is the conversion factor from Einstein to Joule. Hence, Eqn. 9 with Eqns. 10 and 11 follow. 


$$
\begin{gathered}
\Theta=f_{\mathrm{EJ}} I_{0} t \\
\frac{\mathrm{d} x}{\mathrm{~d} \Theta}=-\tilde{a}_{\mathrm{dir}} x-\tilde{a}_{\mathrm{sens}} \frac{b x}{1+b x} \\
\tilde{a}_{\mathrm{dir}}=\frac{a_{\mathrm{dir}}}{f_{\mathrm{EJ}} I_{0}}=\frac{\ln (10) \varepsilon_{\mathrm{R}} \phi_{\mathrm{dir}}}{f_{\mathrm{EJ}}} \\
\tilde{a}_{\mathrm{sens}}=\frac{a_{\mathrm{sens}}}{f_{\mathrm{EJ}} I_{0}}=\frac{\ln (10) \varepsilon_{\mathrm{sens}} c_{\mathrm{sens}} \sqrt{D \tau_{0} \phi_{\mathrm{sens}}^{0}}}{f_{\mathrm{EJ}} \sigma_{0}}
\end{gathered}
$$

For the direct reaction in the absence of a sensitizer, Eqn. 2 reduces to a pure firstorder rate law with a simple exponential as a solution. From the fit to the experimental points, we obtained $\tilde{a_{\mathrm{dir}}}=0.25 \mathrm{~J}^{-1} \mathrm{~cm}^{2}$. For the fit of the kinetics of the sensitized reaction, we used the full analytical solution of the rate law in Eqn. 4, i.e., Eqn. 12. As mentioned above, the sensitized reaction remains diffusion-controlled almost until the end of the reaction, which is tantamount to having $b \rightarrow \infty$. Thus, only the parameter $a_{\text {sens }}$ remained to be determined, for which a value of $\tilde{a_{\text {sens }}}=0.24 \mathrm{~J}^{-1} \mathrm{~cm}^{2}$ was found.

$$
\frac{\ln x}{\tilde{a}_{\mathrm{dir}}+\tilde{a}_{\mathrm{sens}} b}+\frac{1}{\tilde{a}_{\mathrm{dir}}} \frac{\tilde{a}_{\mathrm{sens}} b}{\tilde{a}_{\mathrm{dir}}+\tilde{a}_{\mathrm{sens}} b} \ln \frac{\tilde{a}_{\mathrm{dir}}+\tilde{a}_{\mathrm{sens}} b+\tilde{a}_{\mathrm{dir}} b x}{\tilde{a}_{\mathrm{dir}}+\tilde{a}_{\mathrm{sens}} b+\tilde{a}_{\mathrm{dir}} b}=-\Theta
$$

Exposure Optimization. We developed a new assay for determining optimal exposure times for microarray synthesis. On a single microarray, we built oligonucleotides using different exposures ranging from 1 to $10 \mathrm{~J} / \mathrm{cm}^{2}$. This produced a set of features with the first feature having oligonucleotides synthesized with exposures of $1 \mathrm{~J} / \mathrm{cm}^{2}$ per deprotection step, the second having oligonucleotides synthesized with exposures of $2 \mathrm{~J} / \mathrm{cm}^{2}$, and so forth, up to oligonucleotides synthesized with exposures of $10 \mathrm{~J} / \mathrm{cm}^{2}$. All of the features were intended to have the same sequence; however, incomplete deprotection should produce a deletion event, which would decrease hybridization efficiency. Thus, we expected features containing oligonucleotides synthesized with insufficient deprotection to hybridize less efficiently than features containing oligonucleotides synthesized with sufficient deprotection.

We synthesized these exposure-optimization arrays using $9 H$-thioxanthen-9-one, 2 chloro-9H-thioxanthen-9-one, 4,4'-bis(dimethylamino)benzophenone, or no sensitizer. All of the sensitizers were used at $0.01 \% \mathrm{w} / \mathrm{v}$ in the exposure solvent. The arrays were hybridized under stringent conditions to a $C y$ - $3{ }^{\circledR}$-labelled target oligonucleotide. The results are shown in Fig. 4. The 9H-thioxanthen-9-one accelerated the reaction more than the other sensitizers and created an optimal exposure of $4 \mathrm{~J} / \mathrm{cm}^{2}$. The 2-chloro- $9 H$ thioxanthen-9-one and 4,4'-bis(dimethylamino)benzophenone also accelerated the reaction, but not as much as $9 H$-thioxanthen-9-one. All three sensitizers produced arrays that reached an optimal exposure beyond which hybridization efficiency decreased. This effect was not observed in the deprotection studies shown in Fig. 3.

Yield Studies. Using the exposure time derived from the exposure-optimization arrays, we determined the stepwise yield of the bases with a method described previously [7]. Briefly, we built a series of features composed of different-length 
Optimal Exposure Conditions

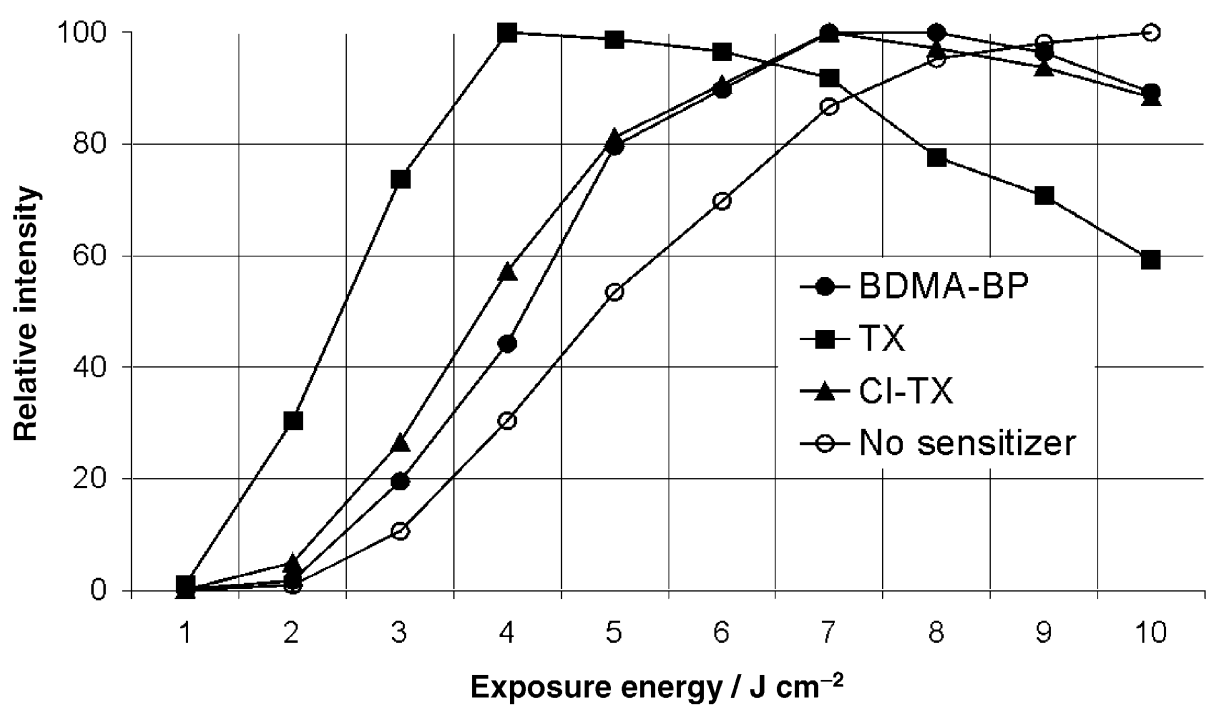

Fig. 4. Determination of optimal exposure conditions. Four exposure optimization arrays were synthesized by using 4,4'-bis(dimethylamino)benzophenone (BDMA-BP), 9H-thioxanthen-9-one (TX), 2-chloro- $9 H$-thioxanthen-9-one (Cl-TX), or no sensitizer. Each array had ten different sets of features. Each set of features contained probe oligonucleotides that were synthesized with different exposures ranging from $1 \mathrm{~J} / \mathrm{cm}^{2}$ to $10 \mathrm{~J} /$ $\mathrm{cm}^{2}$. The arrays were hybridized with $C y-3^{\circledR}$-labelled target and scanned. Background was calculated from control features that received no exposure and then subtracted from all the other features.

oligonucleotides ranging from $0-12$ bases. After synthesis of the oligonucleotides, all the features were deprotected, and $C y-3^{\circledR}$ amidite was coupled to the terminal $\mathrm{OH}$ groups. The resulting fluorescent image provided a relative measure of the remaining $\mathrm{OH}$ groups. This method can be used to estimate the stepwise yield of the chemical synthesis.

We determined the yield for all four bases with and without $9 H$-thioxanthen-9-one. The results are shown in Table 4. The average yield for the bases by using $9 \mathrm{H}$ thioxanthen-9-one was $97 \%$, which is only slightly lower than the average yield of 97.5\% obtained without using $9 H$-thioxanthen-9-one.

Limit of Detection (LOD) Curves. To test the limit of detection of microarrays synthesized by using $9 H$-thioxanthen-9-one as a sensitizer, we placed six control oligonucleotides on the microarray. We hybridized the microarray to a target cocktail containing six $C y-3{ }^{\circledR}$-labelled target oligonucleotides complementary to the probes on the microarray. The target oligonucleotides ranged in concentration from $1 \mathrm{pm}$ to 300 pm. The results of these experiments are shown in Fig. 5. The LOD curves for microarrays synthesized with and without $9 H$-thioxanthen-9-one had essentially the same shape, and both types of microarrays easily detected the 1 pM target.

Replicate Data from Human Arrays. To test the utility of the sensitizers for microarray manufacturing, we synthesized six custom human microarrays using $9 \mathrm{H}$ - 
Table 4. Stepwise Yield $^{\mathrm{a}}$ ) for Direct and Sensitized Photoreaction ${ }^{\mathrm{b}}$ )

\begin{tabular}{|c|c|c|c|c|c|}
\hline & nppoc- $(\operatorname{tac}) A_{d}$ & nppoc-(ibu) $C_{d}$ & nppoc-(ipac) $G_{d}$ & nppoc-T & Average \\
\hline $\begin{array}{l}\text { Stepwise yield [\%] with } \\
9 H \text {-thioxanthen-9-one }\end{array}$ & 98 & 96 & 95 & 99 & 97 \\
\hline $\begin{array}{l}\text { Stepwise yield [\%] with } \\
9 H \text {-thioxanthen-9-one }\end{array}$ & 96 & 99 & 97 & 98 & 97.5 \\
\hline
\end{tabular}

a) Arrays that had sets of thirteen different features were synthesized. The features had oligonucleotides of different length ranging from 0 to 12 bases. After synthesis, all the features were deprotected and coupled to $C y$ $3^{\circledR}$ amidite to quantify the relative amount of free $\mathrm{OH}$ groups on the terminal ends of the oligonucleotides. From this, the relative stepwise yields of the chemical synthesis were estimated as described in [7]. $\left.{ }^{\mathrm{b}}\right)$ tac $=($ tertButylphenoxy)acetyl, isomeric mixture, $\mathrm{ibu}=$ isobutyryl, ipac = (isopropylphenoxy)acetyl, isomeric mixture.

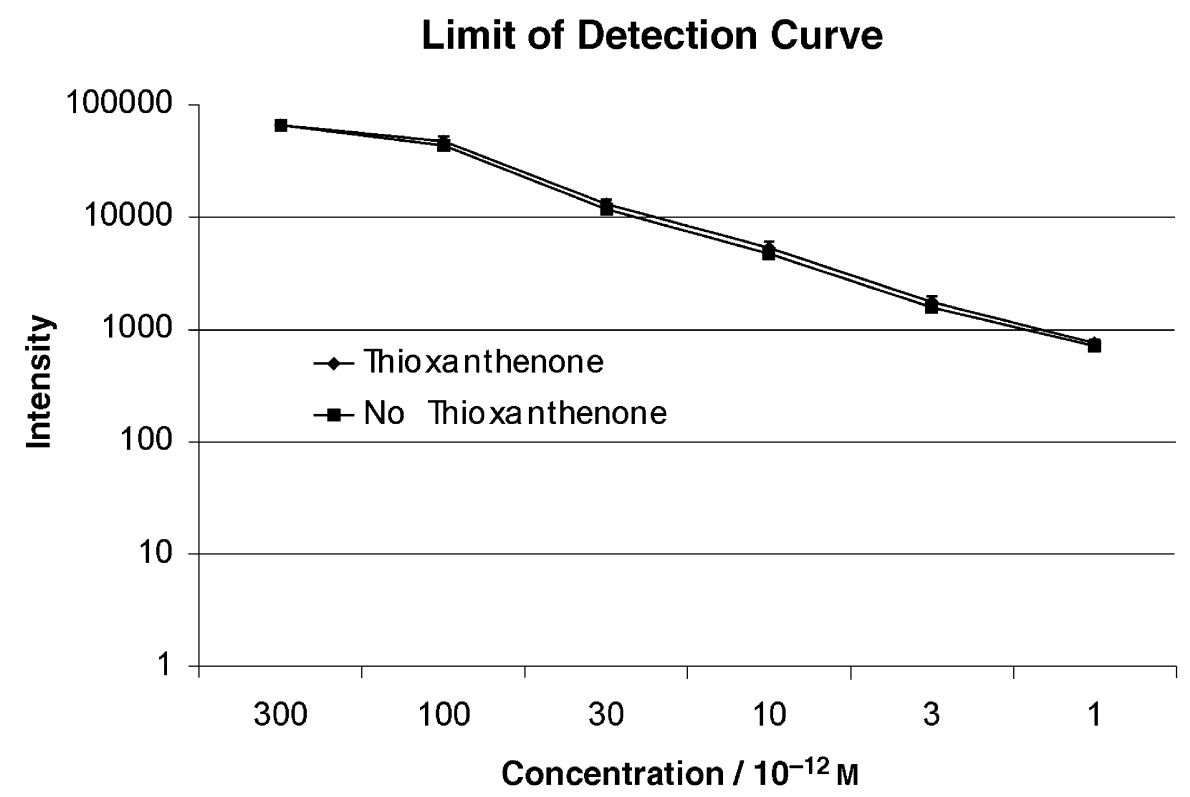

Fig. 5. Determination of limit of detection. The sensitivity of arrays synthesized using $9 H$-thioxanthen-9-one in the exposure solvent was estimated by creating arrays with probes complementary to a control oligonucleotide cocktail containing $C y-3^{\circledR}$-labelled targets ranging in concentration from 300 pm to 1 pm. The arrays were hybridized for $2 \mathrm{~h}$, washed stringently, and scanned at PMT settings that saturated the 300 рм features.

thioxanthen-9-one in the exposure solvent. Samples were prepared for hybridization by the method similar to that described previously [2]. We split each sample preparation between three arrays to quantify the reproducibility of the arrays synthesized with $9 \mathrm{H}$ thioxanthen-9-one. Fig. 6, $a$, shows replicate data for two of the arrays that contained hybridized sample from total human brain. The $r^{2}$ value is 0.9937 , which indicates a high degree of reproducibility. Fig. $6, b$ shows a plot comparing total human brain vs. hippocampus (data shown in Table 5). 
Discussion. - As shown above (Results), the effect of the sensitizer on the photokinetics can be modelled in a physically consistent way. Thus, this simulation represents clear evidence of the diffusion-controlled triplet-triplet energy transfer mechanism of sensitization, which can be made effective both in homogeneous solution and on a chip. With regard to the sensitizer, the absorbance is constant because its concentration is constant during the whole process. Therefore, it is expected that, in case of a dominating contribution of the sensitized reaction pathway, as compared to the direct pathway, the reaction should proceed with a zero-order rate law, as long as the photolabile acceptors efficiently quench the sensitizer. However, such behavior is apparent only for the reaction on the chip, not in homogeneous solution. In this latter situation, the quenching of excited sensitizer triplets by product molecules resulting from the released photolabile group is a plausible explanation, because the value of the quenching rate constant, determined upon such a hypothesis, is found in a physically sensible range. The different geometric situation on the chip, i.e., the relevance of only those sensitizer molecules that are excited within the narrow diffusion zone of width $\sqrt{\mathrm{D} \tau_{0}}$, provides a natural explanation of the fact that the cleaved photolabile moieties are not as effective as they are in homogeneous solution. Because the released products escape from the diffusion zone and are washed away with the bulk solution, their concentration in the diffusion zone cannot rise high enough to become effective for the quenching of excited sensitizer molecules. This effect is particularly true if the lifetime of the sensitizer triplets is shortened by the presence of $\mathrm{O}_{2}$, which leads to a narrowing of the width of the diffusion zone.

The parameters $a_{\mathrm{dir}}$ and $a_{\text {sens }}$ obtained from the simulation of the kinetics on the chip hold interesting information that can be accessed from Eqns. 10 and 11. With $f_{\mathrm{EJ}}$ $(366 \mathrm{~nm})=0.33 \cdot 10^{6} \mathrm{~J} \mathrm{E}^{-1}, \varepsilon_{\mathrm{R}}(366 \mathrm{~nm})=2.47 \cdot 10^{5} \mathrm{~cm}^{2} \mathrm{~mol}^{-1}$, and $\tilde{a_{\mathrm{dir}}}=0.25 \mathrm{~J}^{-1} \mathrm{~cm}^{2}$, we obtain from Eqn. $10 \phi_{\text {dir }}=0.14$, a value of the quantum yield that is not unreasonable, albeit somewhat lower than that typically measured in solution (cf. Table 3).

By combining Eqns. 10 and 11 and using the experimental values of $\tilde{a_{\text {dir }}}$ and $\tilde{a_{\text {sens }}}$, we obtain Eqn. 13.

This equation allows us to estimate the initial surface density $\sigma_{0}$ of photoreactive groups on the chip. With $c_{\text {sens }}=5 \cdot 10^{-4} \mathrm{M}, D=5 \cdot 10^{-6} \mathrm{~cm}^{2} \mathrm{~s}^{-1}$ (as estimated by the Stokes-Einstein equation), $\tau_{0}=300 \mathrm{~ns}$ (as measured in air-saturated solution), $\varepsilon_{\text {sens }}$ $(366 \mathrm{~nm})=4.9 \cdot 10^{6} \mathrm{~cm}^{2} \mathrm{~mol}^{-1}$ and $\phi_{\text {sens }}^{0}=\phi_{\text {dir }}$, assuming that the quantum yield $\phi_{\text {sens }}^{0}$ after triplet-triplet energy transfer is about the same as $\phi_{\text {dir }}$, which is borne out by the data for liquid solution, we obtain $\sigma_{0}=8 \cdot 10^{12}$ molecules $/ \mathrm{cm}^{2}$, which seems a very reasonable estimate [17].

$$
\frac{\sigma_{0} \varepsilon_{\mathrm{R}} \phi_{\mathrm{dir}}}{c_{\text {sens }} \sqrt{D \tau_{0}} \varepsilon_{\text {sens }} \phi_{\text {sens }}^{0}}=\frac{\tilde{a}_{\mathrm{dir}}}{\tilde{a}_{\text {sens }}}=1.0
$$

The results presented for the humane-genome microarrays have demonstrated that, under practical conditions on a chip, $9 H$-thioxanthen-9-one can reduce the required exposure time to $1 / 3$ of the normal exposure time. This is due to $i$ ) the general acceleration of the photolysis by sensitization and $i$ ) an effective change of the reaction order from one to zero, whereby the termination of the reaction is defined much more precisely. 
a)

Total Human Brain

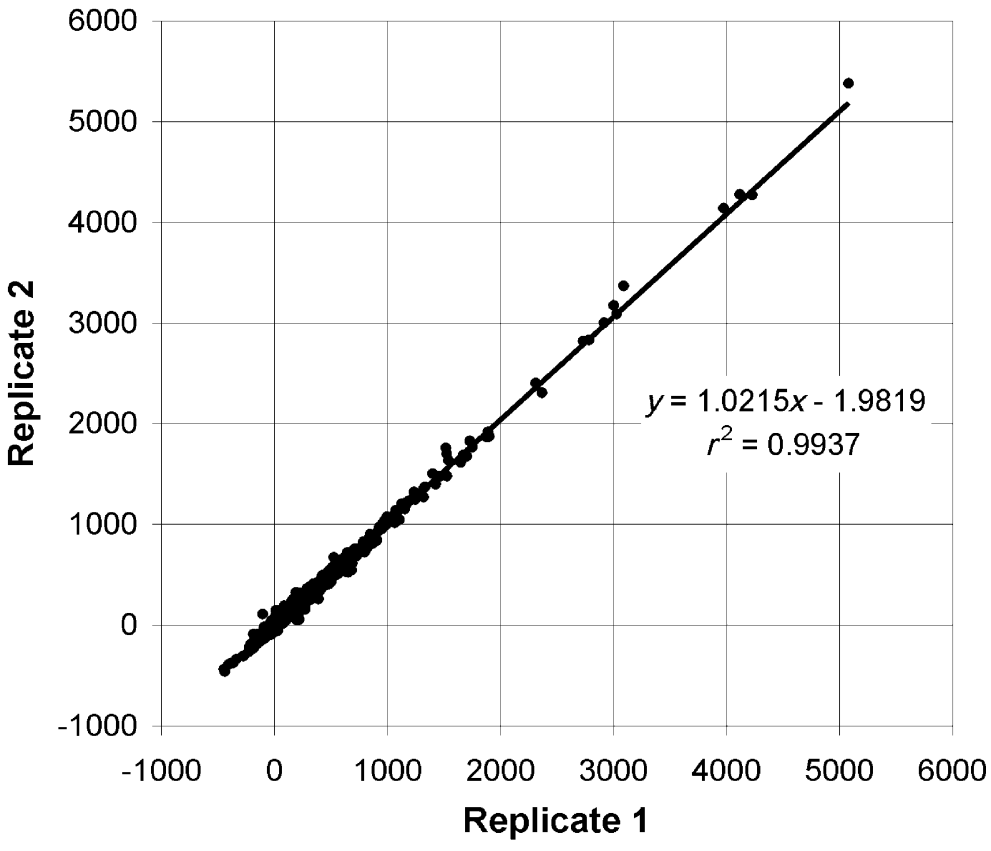

b) Total Human Brain vs. Hippocampus

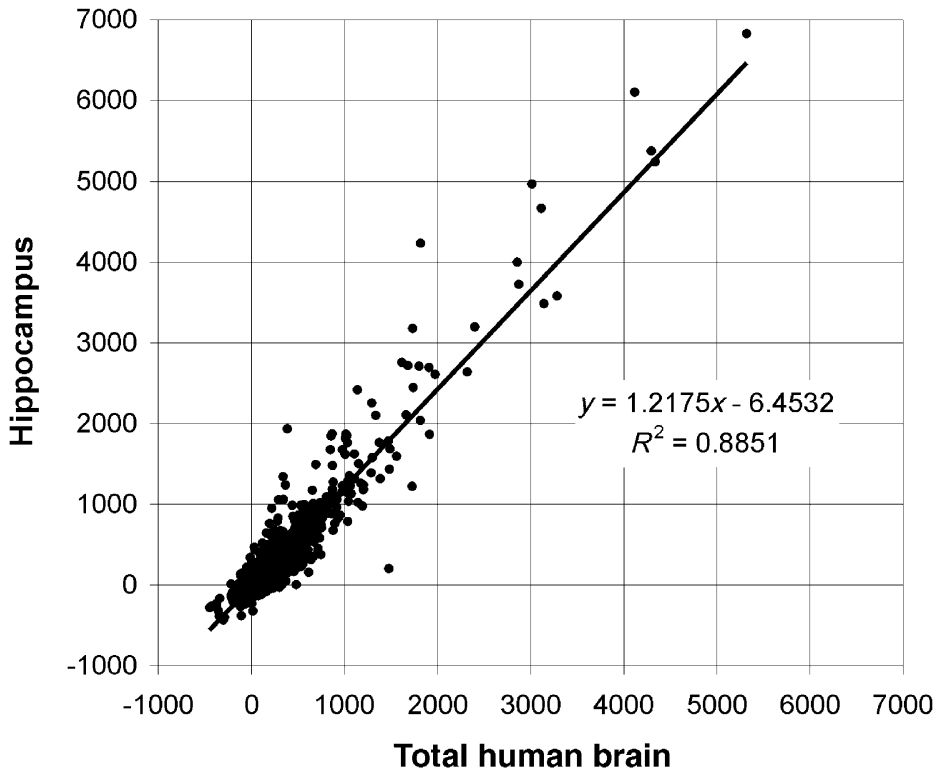

Fig. 6. a) Replicate data from human microarray experiments (two replicate experiments with total human brain RNA were compared; the average difference values for the genes were compared in the scatter plot and the $r^{2}$ value was calculated). b) Comparison of total human brain vs. hippocampus (the average difference of three replicates for both total human brain and hippocampus were compared in a scatter plot). 
Table 5. Differentially Expressed Genes between Total Human Brain vs. Human Hippocampus Tissue ${ }^{\mathrm{a}}$ )

\begin{tabular}{|c|c|c|}
\hline Fold change & Seq ID & Function \\
\hline 5.0 & HSAP0028S00000207 & SPARC-like 1 (mast9, hevin) (SPARCL1), mRNA \\
\hline 4.5 & HSAP0028S00001957 & $\begin{array}{l}\text { similar to deleted in polyposis } 1 \text {, clone MGC: } 2267 \text { IMAGE: } 3350749 \text {, } \\
\text { mRNA, complete cds. }\end{array}$ \\
\hline 4.4 & HSAP0028S00006365 & CDC10 cell division cycle 10 homolog ( $S$. cerevisiae) $(\mathrm{CDC} 10)$, mRNA \\
\hline 4.0 & HSAP0028S00004642 & RY-1 mRNA for putative nucleic acid binding protein \\
\hline 4.0 & HSAP0001S00000323 & heat shock $90 \mathrm{kD}$ protein $1, \alpha$ (HSPCA), mRNA \\
\hline 4.0 & HSAP0028S00002836 & KIAA0871 protein (KIAA0871), mRNA \\
\hline 3.6 & HSAP0028S00000018 & matrin 3 (MATR3), mRNA \\
\hline 3.4 & HSAP0028S00000153 & stathmin-like 2 (STMN2), mRNA \\
\hline 3.1 & HSAP0028S00002852 & GW128 protein (GW128), mRNA \\
\hline 3.0 & HSAP0028S00001545 & $\begin{array}{l}\text { cDNA FLJ32993 fis, clone THYMU1000103, weakly similar to } \\
\text { protein kinase C, } \beta \text {-I type (EC 2.7.1.-) }\end{array}$ \\
\hline 3.0 & HSAP0028S00001939 & nucleosome assembly protein 1 -like 1 , clone \\
\hline 2.9 & HSAP0028S00001457 & $\begin{array}{l}\text { MGC : } 8688 \text { image : } 2964631, \text { mRNA, complete cds. } \\
\text { serine (or cysteine) proteinase inhibitor, clade I (neuroserpin), } \\
\text { member } 1 \text { (SERPINI1), mRNA }\end{array}$ \\
\hline 2.9 & HSAP0028S00001329 & hypothetical protein (HSPC014), mRNA \\
\hline 2.8 & HSAP0028S00006428 & similar to rat nuclear ubiquitous casein kinase 2 (NUCKS), mRNA \\
\hline 2.8 & HSAP0028S00002114 & $\begin{array}{l}\text { NADH dehydrogenase (ubiquinone) } 1 \alpha \text { subcomplex, } 5 \text { ( } 13 \mathrm{kD}, \mathrm{B} 13) \\
\text { (NDUFA5), nuclear gene encoding mitochondrial protein, mRNA }\end{array}$ \\
\hline 2.4 & HSAP0028S00002040 & $\begin{array}{l}\text { oxysterol-binding protein-related protein (ORP1) mRNA, } \\
\text { complete cds. }\end{array}$ \\
\hline 2.3 & HSAP0001S00002101 & calmodulin 2 (phosphorylase kinase, $\delta$ ) (CALM2), mRNA \\
\hline 2.3 & HSAP0028S00000451 & $\begin{array}{l}\text { similar to DnaJ (Hsp40) homolog, subfamily A, member } 1 \\
\text { (H. sapiens) (LOC158188), mRNA }\end{array}$ \\
\hline 2.3 & HSAP0028S00002957 & $\begin{array}{l}\text { platelet-activating factor acetylhydrolase, isoform } \mathrm{Ib}, \alpha \text { subunit } \\
(45 \mathrm{kD}) \text { (PAFAH1B1), mRNA }\end{array}$ \\
\hline 2.3 & HSAP0028S00000222 & visinin-like 1 (VSNL1), mRNA \\
\hline 2.2 & HSAP0028S00000203 & kinesin family member 5C ( KIF 5C), mRNA \\
\hline 2.2 & HSAP0028S00004016 & chimerin (chimaerin) 1 (CHN1), mRNA \\
\hline 2.2 & HSAP0028S00006787 & lactate dehydrogenase B (LDHB), mRNA \\
\hline 2.2 & HSAP0028S00006731 & calmodulin 1 (phosphorylase kinase, $\delta$ ) (CALM1), mRNA \\
\hline 2.2 & HSAP0028S00003282 & $\begin{array}{l}\text { solute carrier family } 1 \text { (glial high affinity glutamate transporter), } \\
\text { member } 3 \text { (SLC1A3), nuclear gene encoding mitochondrial } \\
\text { protein, mRNA }\end{array}$ \\
\hline 2.1 & HSAP0001S00001726 & ribosomal protein L26 (RPL26), mRNA \\
\hline 2.1 & HSAP0028S00000120 & KIAA0438 gene product (KIAA0438), mRNA. \\
\hline 2.1 & HSAP0028S00000039 & numb homolog (Drosophila) (NUMB), mRNA \\
\hline 2.1 & HSAP0028S00003283 & mannose-P-dolichol utilization defect 1 (MPDU1), mRNA \\
\hline 2.0 & HSAP0028S00002387 & $\begin{array}{l}\text { synuclein, } \alpha \text { (non A4 component of amyloid precursor) (SNCA), } \\
\text { transcript variant NACP140, mRNA }\end{array}$ \\
\hline 2.0 & HSAP0001S00001332 & malate dehydrogenase 1 , NAD (soluble) (MDH1), mRNA \\
\hline 2.0 & HSAP0028S00002417 & $\begin{array}{l}\text { UDP- } N \text {-acetyl- } \alpha \text {-D-galactosamine:( } N \text {-acetylneuraminyl)galactosyl- } \\
\text { glucosylceramide } N \text {-acetylgalactosaminyltransferase (GalNAc-T) } \\
\text { (GALGT), mRNA }\end{array}$ \\
\hline 1.9 & HSAP0028S00004949 & Golli-mbp gene, complete cds. \\
\hline 1.9 & HSAP0028S00002188 & ovarian carcinoma immunoreactive antigen (OCIA), mRNA \\
\hline 1.9 & HSAP0028S00001862 & progesterone receptor membrane component 1 (PGRMC1), mRNA \\
\hline 1.9 & HSAP0028S00004054 & ras homolog gene family, member $\mathrm{G}(\rho \mathrm{G})$ (ARHG), mRNA \\
\hline 1.9 & HSAP0001S00001318 & capping protein (actin filament) muscle Z-line, $\alpha 1$ (CAPZA1), mRNA \\
\hline 1.9 & HSAP0028S00002523 & $\begin{array}{l}\text { prion protein }(\mathrm{p} 27-30)(\text { Creutzfeld-Jakob disease, } \\
\text { Gerstmann-Strausler-Scheinker syndrome, fatal familial insomnia) } \\
(\mathrm{PRNP}), \text { mRNA }\end{array}$ \\
\hline
\end{tabular}

a) The array contained 4815 human gene sequences with 19 probe pairs per gene. Each probe pair consisted of a perfect match and mismatch sequence. Fold-change values were calculated from normalized average difference values of the probe sets. 
Finally, we mention that we also studied the effect of removing $\mathrm{O}_{2}$ from the exposure solvent during the synthesis of oligonucleotides on the microarrays. The absence of $\mathrm{O}_{2}$ increased the speed of the reaction considerably. Unfortunately, microarrays made under these conditions were nonuniform, and it has not been possible yet to reliably manufacture microarrays with sensitizers in the absence of $\mathrm{O}_{2}$. A reason for this might be that the large increase in light sensitivity due to the long triplet life time in the absence of $\mathrm{O}_{2}$ compresses, in effect, the time scale of the diagram shown in Fig. 4, so that the optimal exposure time may have been exceeded and, under the prevailing conditions, a deteriorating side effect of the sensitizer may have appeared. Further studies to clarify this issue are under way.

We thank Dr. Nikita Lukzen for valuable disscussions.

\section{Experimental Part}

Laser Flash Experiments. Samples were excited by a frequency tripled Nd-YAG-laser (Spectra Physics Quanta Ray GCR 150, $355 \mathrm{~nm}$, repetition rate $5 \mathrm{~Hz}$, pulse width $4-6 \mathrm{~ns}$ ). The pulse energy of $100 \mathrm{~mJ}$ was reduced to $c a .30 \mathrm{~mJ}$ by neutral density filters. The optical detection system for transient absorption involved a Xe lamp (Osram XBO 150), a f/3.4 monochromator (Applied Photophysics), and a photomultiplier (Hamamatsu $R$ 955) or an intensified CCD camera (PI-MAX Princeton Instruments). The photomultiplier signal was recorded by a digital oscilloscope (LeCroy 9354A) and the data transmitted to a personal computer. The CCD data were processed with the WinSpec/32 software package.

Continuous Irradiations in Solution. The caged compounds 5'-O-\{[2-(2-nitrophenyl)propoxy]carbonyl $\}-$ thymidine (nppoc-T) [18] and 2-(2-nitrophenyl)propyl acetate (npp-Ac) [11] used for all experiments in homogeneous solution were synthesized as described previously. The light source for continuous irradiation was a high-pressure $\mathrm{Hg}$ lamp (Osram HBO 200). The light was passed through a heat filter (optical length $5 \mathrm{~cm}$, filled with sat. $\mathrm{CuSO}_{4}$ soln. in $\mathrm{H}_{2} \mathrm{O}$ ), a collimating lens, an electronic shutter, a 366-nm interference filter (Schott) and a thermostated optical-cell holder with a cell of 1-cm path length (Hellma QS), equipped with a magnetic stirring bar. The light flux was determined by using an azobenzene actinometer. Typical values were ca. $3 \cdot 10^{-8} \mathrm{E} \mathrm{cm}^{-2} \mathrm{~s}^{-1}$. The cell was filled with $3 \mathrm{ml}$ of the probe solns. and sealed by a rubber septum. It was purged with $\mathrm{N}_{2}$ for $15 \mathrm{~min}$ and irradiated for fixed intervals of time. UV/VIS Absorption spectra were recorded on a Cary Lambda-18 spectrometer before and after irradiation. Reactants and products were separated and quantitated by HPLC. HPLC: Merck-Hitachi HPLC system including a LiChrospher-100-RP-18 $(5 \mu \mathrm{m})$ column, a $L-7100$ pump, a $L-7200$ autosampler, a $L-7450 A$ UV diode array detector, and a $L-7000$ interface with the HSM-manager software; gradient from pure $\mathrm{H}_{2} \mathrm{O}$ to pure $\mathrm{MeCN}$.

Array Synthesis. Standard DNA synthesis reagents (Glen Research, Sterling, VA; Proligo, Boulder, CO; Amersham Pharmacia, Piscataway, NJ; Applied Biosystems, Foster City, CA) were used on Expedite DNA synthesizers (Applied Biosystems). The photolabile phosphoramidites 2'-deoxy-5'-O-\{[2-(2-nitrophenyl)propoxy]carbonyl\}- $N^{6}$-[(tert-butylphenoxy)acetyl, isomeric mixture ]adenosine $3^{\prime}$-(2-cyanoethyl phosphoramidite) (nppoc-(tac) $\left.{ }^{6} \mathrm{~A}_{\mathrm{d}}-\mathrm{p}^{\prime}(\mathrm{CNEt})\right), 2^{\prime}$-deoxy- $N^{4}$-isobutyryl-5'-O-\{[2-(2-nitrophenyl)propoxy]carbonyl $\}$ cytidine 3 '-(2cyanoethyl phosphoramidite) (nppoc-(ibu $\left.)^{4} \mathrm{C}_{\mathrm{d}}-\mathrm{p}^{\prime}(\mathrm{CNEt})\right), 2^{\prime}$-deoxy- $N^{2}$-[(isopropylphenoxy)acetyl, isomeric mixture]-5'-O-\{[2-(2-nitrophenyl)propoxy]carbonyl \}guanosine 3'-(2-cyanoethyl phosphoramidite) (nppoc(ipac) $\left.)^{2} \mathrm{G}_{\mathrm{d}}-\mathrm{p}^{\prime}(\mathrm{CNEt})\right)$, and 5'-O-\{[2-(2-nitrophenyl)propoxy]carbonyl $\}$ thymidine 3'-(2-cyanoethyl phosphoramidite) (nppoc-T-p'(CNEt)) ( $\mathrm{p}^{\prime}=$ phosphoramidite) were from Proligo. The maskless-array-synthesizer (MAS) units (NimbleGen Systems, Madison, WI) were connected to the Expedites to manufacture the custom arrays. Arrays were designed using ArrayScribe ${ }^{\mathrm{TM}}$ software (http://www.nimblegen.com/arrayscribe) (NimbleGen Systems). After the synthesis on the MAS units was completed, the base-protecting groups were removed in a soln. of ethane-1,2-diamine/EtOH 1:1 (v/v) (Aldrich, St. Louis, MO) for 2 h. The arrays were rinsed with $\mathrm{H}_{2} \mathrm{O}$, dried, and stored desiccated until use.

Deprotection Measurements. Deprotection studies were performed to determine deprotection rates on arrays [7]. We started with a slide that had a monolayer of nppoc-protected nucleotides attached to the surface. Exposures were carried out in NimbleGen exposure soln. (NimbleGen Systems) with the addition of one or none of the following: $0.01 \%(w / v) \quad 4,4^{\prime}$-bis(dimethylamino)benzophenone, $0.01 \%$ ( $w / v$ ) 2-chloro-9H- 
thioxanthen-9-one, or $0.01 \%$ 9H-thioxanthen-9-one (Aldrich, Milwaukee, WI). After the exposures were completed, $C y-3^{\circledR}$ amidite (Amersham Pharmacia) was coupled to the surface, and the slides were deprotected and scanned.

Exposure Optimization. We synthesized a series of features that each had a control oligonucleotide sequence (5'-AGGTCATTACAGCGAGAG-3'). One set of features was synthesized with exposures of $1 \mathrm{~J} / \mathrm{cm}^{2}$, a second with exposures of $2 \mathrm{~J} / \mathrm{cm}^{2}$, and so forth, up to features with exposures of $10 \mathrm{~J} / \mathrm{cm}^{2}$. After synthesis, the arrays were deprotected and hybridized to a control oligonucleotide for $2 \mathrm{~h}$ in the presence of $50 \mathrm{~mm}$ MES (morpholine-4-ethanesulfonic acid, sodium salt), $0.5 \mathrm{M} \mathrm{NaCl}, 10 \mathrm{~mm}$ EDTA, and $0.005 \%$ ( $/ \mathrm{v}$ ) Tween-20 at $45^{\circ}$. After hybridization, arrays were washed in nonstringent (NS) buffer ( $6 X$ SSPE, $0.01 \%(v / v)$ Tween 20$)$ for 5 min at r.t., then washed in stringent buffer (100 mu MES, $0.1 \mathrm{M} \mathrm{NaCl}, 0.01 \%$ Tween 20$)$ for $30 \mathrm{~min}$ at $45^{\circ}$, followed by a 5 min wash in NS buffer and a $30 \mathrm{~s}$ rinse in 1 X NimbleGen final rinse buffer (NimbleGen Systems).

Yield Studies. Custom arrays were designed to study the repetitive yield of four photolabile phosphoramidites: nppoc-(tac $)^{6} \mathrm{~A}_{\mathrm{d}}-\mathrm{p}^{\prime}(\mathrm{CNEt})$, nppoc-(ibin $)^{4} \mathrm{C}_{\mathrm{d}}-\mathrm{p}^{\prime}(\mathrm{CNEt})$, nppoc-(ipac $)^{2} \mathrm{G}_{\mathrm{d}}-\mathrm{p}^{\prime}(\mathrm{CNEt})$, and nppoc-T$\mathrm{p}^{\prime}(\mathrm{CNEt})\left(\mathrm{p}^{\prime}=\right.$ phosphoramidite $)$ (Proligo). The arrays had features containing oligonucleotides ranging from 1 to 12 bases long. After synthesizing the features, biotin phosphoramidite (Glen Research) was coupled to all of the features. The arrays were deprotected and then placed in streptavidin-Cy-3 ${ }^{\circledR}$ (Amersham Pharmacia) buffer for $10 \mathrm{~min}$, washed with NS buffer and rinsed for $30 \mathrm{~s}$ with $1 X$ NimbleGen final rinse buffer (NimbleGen Systems).

Limit-of-Detection Study. We designed six probes for spike-in controls on arrays to measure the dynamic range and limit of detection of the arrays. We ordered $C y-3^{\circledR}$-labelled targets for the probes from $I D T$ (Skokie, IL). The spike-in controls were added to the hybridization cocktail at the following concentrations: 300, 100, 30, 10,3 , and 1 pM. The sequences of the spike-ins, from high to low concentrations, were: $5^{\prime} C y$-3gcaacagcaggggcgatatcctct $3^{\prime}, 55^{\prime} \mathrm{Cy}$-3tgatgatgcgctcagtgccatgcg3', 5' $\mathrm{Cy}$-3ttctgggtgcataccagtcttacc $3^{\prime}, 5^{\prime} \mathrm{Cy}$-3tcctgtctcccgatgaaaacatat $3^{\prime}, 5^{\prime} C y$-3cgcctacaaaagccagtttatccc $3^{\prime}$, and $5^{\prime} C y$-3cactgtcatcagaatctgtcggec $3^{\prime}$, resp. We also designed two basemismatch controls for the spike-ins with the following sequences (the mismatch bases are in capital letters): gcaacTgcaggCgcgatatcctct, tgatgTtgcgcAcagtgccatgcg, ttctgCgtgcaAaccagtcttacc, tcctgActcccCatgaaaacatat, cgcctTcaaaaCccagtttatccc, cactgAcatcaCaatctgtcggcc.

Human Array Design. The array contained 4815 human sequences, all publicly available from GenBank (http://www.ncbi.nlm.nih.gov/). Nineteen probes, each 24 base pairs in length, were selected for each gene, and each had a corresponding mismatch probe. The mismatch probes had two mismatches, at position 6 and position 12. Mismatches were created by changing A to T, C to G, G to C, and T to A. Probe pairs for each gene were randomly distributed across the array.

Hybridization and Washing. Microarrays were hybridized with $10 \mu \mathrm{g}$ of cRNA in $300 \mu \mathrm{l}$ in the presence of $50 \mathrm{~mm}$ MES, 0.5 M NaCl, $10 \mathrm{~mm}$ EDTA, and $0.005 \%$ ( $v / v)$ Tween-20 for $16 \mathrm{~h}$ at $45^{\circ}$. Before application to the array, samples were heated to $95^{\circ}$ for $5 \mathrm{~min}$, then heated to $45^{\circ}$ for $5 \mathrm{~min}$, and spun at $14000 \cdot \mathrm{g}$ for $5 \mathrm{~min}$. Hybridization was performed in a custom-designed hybridization chamber (NimbleGen Systems) and rotated in a hybridization oven. After hybridization, arrays were washed in NS buffer for $5 \mathrm{~min}$ at r.t., followed by washing in stringent buffer for $30 \mathrm{~min}$ at $45^{\circ}$. After washing, arrays were stained with streptavidin- $C y-3^{\circledR}$ conjugate (Amersham Pharmacia) for $25 \mathrm{~min}$ at r.t., which was followed by a 5-min wash in NS buffer, a 30 -s rinse in $1 X$ NimbleGen final rinse buffer, and a spin-dry in a custom-designed array centrifuge (NimbleGen Systems).

Data Analysis. Prior to data extraction, images were doubled in size (without interpolation) by using ImageJ software (http://rsb.info.nih.gov/ij/). Features were extracted with GenePix 3.0 software (Axon Instruments, Inc., Union City, CA), based on a fixed feature size. The local background correction from the GenePix software was not applied to raw signal intensities. Gene-expression values were calculated by subtracting the mismatch signal from the perfect-match signal, discarding values greater than 3.0 standard deviations from the average, and then averaging the remaining values. Replicate-gene-expression values were scaled by dividing each value by the standard deviation of the expression values for the array, after discarding the lower and upper $2.5 \%$ of the data, and then multiplying by the standard deviation of all expression values from all replicate arrays. 


\section{REFERENCES}

[1] A. C. Pease, D. Solas, E. J. Sullivan, M. T. Cronin, C. P. Holmes, S. P. A. Fodor, Proc. Natl. Acad. Sci. U.S.A. 1994, $91,5022$.

[2] E. F. Nuwaysir, W. Huang, T. J. Albert, J. Singh, K. Nuwaysir, A. Pitas, T. Richmond, T. Gorski, J. P. Berg, J. Ballin, M. McCormick, J. Norton, T. Pollock, T. Sumwalt, L. Butcher, D. Porter, M. Molla, C. Hall, F. Blattner, M. R. Sussman, R. L. Wallace, F. Cerrina, R. D. Green, Genome Res. 2002, 12, 1749.

[3] T. R. Hughes, M. Mao, A. Jones, J. Burchard, M. J. Marton, J. Schelter, M. R. Meyer, S. Kobayashi, H. Dai, Y. He, S. Stephaniants, A. West, E. Coffey, D. Shoemaker, R. Stoughton, A. Blanchard, S. H. Friend, P. S. Linsley, Nat. Biotechnol. 2001, 19, 342.

[4] X. Gao, P. Yu, E. LeProust, L. Sonigo, J. P. Pellois, H. Zhang, J. Am. Chem. Soc. 1998, 120, 12698.

[5] K. Dill, L. H. Stanker, C. R. Young, J. Biochem. Biophys. Methods 1999, 41, 61.

[6] M. Schena, D. Shalon, R. W. Davis, P. O. Brown, Science (Washington, D.C.) 1995, 270, 467.

[7] G. H. McGall, A. D. Barone, M. Diggelmann, S. P. A. Fodor, E. Gentalen, N. Ngo, J. Am. Chem. Soc. 1997, 119, 5081.

[8] D. Wöll, Diploma Thesis, 2002, Universität Konstanz.

[9] M. C. Pirrung, L. Fallon, G. McGall, J. Org. Chem. 1998, 63, 241.

[10] S. L. Murov, I. Carmichael, G. L. Hug, 'Handbook of Photochemistry', 2nd edn., Marcel Dekker, Inc., New York 1993.

[11] S. Walbert, W. Pfleiderer, U. E. Steiner, Helv. Chim. Acta 2001, 84, 1601.

[12] V. Balzani, F. Bolletta, F. Scandola, J. Am. Chem. Soc. 1980, 102, 2152.

[13] H.-J. Timpe, K.-P. Kronfeld, J. Photochem. Photobiol. A. 1989, 46, 253.

[14] D. G. Anderson, R. S. Davidson, J. J. Elvery, Polymer 1996, 37, 2477.

[15] R. Hurley, A. C. Testa, J. Am. Chem. Soc. 1968, 90, 1949.

[16] D. Wöll, N. Lukzen, U. E. Steiner, in preparation.

[17] M. C. Pirrung, Angew. Chem., Int. Ed. 2002, 41, 1276.

[18] A. Hasan, K.-P. Stengele, H. Giegrich, P. Cornwall, K. R. Isham, R. A. Sachleben, W. Pfleiderer, R. S. Foote, Tetrahedron 1997, 53, 4247. 